Tourism in Analysis

DOI: http://dx.doi.org/10.11606/issn.1984-4867.v27i3p714-731

\title{
Turismo, Lazer e Megaeventos Esportivos no Brasil: relato de experiências sobre as Olimpíadas 2016
}

\author{
Tourism, leisure and sports mega-events in Brazil: \\ experience report on the 2016 Olympics
}

Turismo, ocio y mega-eventos deportivos en Brasil: relato sobre los Juegos Olímpicos de 2016

Ricardo Ricci Uvinha ${ }^{1}$

\begin{abstract}
Resumo
Muito para além do esporte, estima-se que os megaeventos esportivos no período 2007-2016 tenham trazido ao Brasil um inegável impacto em termos de legado para diversos setores, entre eles o de turismo, lazer e hospitalidade. Tem-se como objetivo no presente texto realizar um relato de experiências durante as Olimpíadas Rio 2016. O período compreendido de análise é o de realização do megaevento esportivo: 5 a 21 de agosto de 2016. Para isso, realizou-se uma pesquisa exploratória de âmbito qualitativo, viabilizada por uma observação participante, com a inserção do pesquisador na realidade em que se deram os fatos, no caso a cidade do Rio de Janeiro e também a de São Paulo, que foi uma das cidades do futebol. Tal inserção permitiu confrontar a realidade dos fatos com uma série de postulados teóricos e hipóteses formuladas anteriormente aos Jogos Olímpicos, servindo de excelente exercício para compreender a complexidade na realização deste megaevento esportivo.
\end{abstract}

Palavras-chave: Megaeventos esportivos; Rio de Janeiro; Turismo; Lazer; Hospitalidade.

\begin{abstract}
Way beyond sports, it is estimated that sports mega-events in the period of 2007-2016 have brought to Brazil an undeniable impact in terms of legacy for various sectors, including tourism, leisure and hospitality. The purpose of this paper is to report on experiences during the Rio 2016 Olympics. The analysis was performed during the sports mega-event: from August 5 to August 21, 2016. For that, an exploratory research of a qualitative approach was made through a participant observation, using the insertion of the researcher where the real facts were given, in this case the city of Rio de Janeiro and also the city of São Paulo, one of the soccer cities. This insertion allowed us to confront the reality of the events with a series of

\footnotetext{
1 Doutor em Ciência da Comunicação Pela Escola de Comunicações e Artes da Universidade de São Paulo (ECA-USP). Pós-Doutor pela Griffith University-Austrália. Professor Livre-docente do Programa de Pós-Graduação em Turismo da Universidade de São Paulo (USP). Líder do Grupo Interdisciplinar de Estudos do Lazer da Universidade de São Paulo (GIEL/USP). São Paulo, São Paulo, Brasil. E-mail: uvinha@usp.br
} 
Tourism in Analysis

theoretical postulates and hypothesis formulated before the Olympic Games, serving as an excellent exercise to understand the complexity in the accomplishment of this sports mega-event. Keywords: Sports mega-events; Rio de Janeiro; Tourism; Leisure; Hospitality.

\section{Resumen}

Mucho más allá del deporte, se estima que los grandes eventos deportivos en el periodo 2007-2016 le han producido a Brasil un impacto innegable en términos de legados en varios sectores, además del turismo, el ocio y la hospitalidad. El objetivo de este texto es relatar las experiencias durante los Juegos Olímpicos en Río 2016. El periodo de análisis coincidió con la finalización de este mega-evento deportivo efectuado del 5 al 21 de agosto de 2016. Por tal motivo, se celebró una investigación exploratoria de nivel cualitativo, gracias a la observación de los participantes y la inserción del investigador en la realidad donde se llevaron a cabo los hechos, especificamente en Río de Janeiro y en São Paulo. Esta inserción permitió confrontar la realidad de los hechos con una serie de postulados teóricos y evaluaciones realizadas antes de los Juegos Olímpicos, que sirve como un excelente ejercicio para entender la complejidad de la realización de este mega-evento deportivo.

Palabras clave: Mega-eventos deportivos; Río de Janeiro; Turismo; Ocio; Hospitalidad.

\section{Introdução}

O ano de 2016 encerrou um período conhecido, em diversos meios, como a "década de ouro para o esporte no Brasil": 2007-2016. Isto porque ao menos sete megaeventos esportivos mereceram destaque no cenário internacional por seu forte apelo midiático e potencialidade de impacto em diversos setores. Faz-se referência aqui aos seguintes eventos, sem prejuízo aos diversos outros eventos realizados no período: (1) os Jogos Pan-Americanos Rio 2007; (2) os Jogos Parapan-Americanos Rio 2007; (3) os Jogos Mundiais Militares Rio 2011; (4) a Copa das Confederações FIFA 2013; (5) a Copa do Mundo FIFA 2014; (6) os Jogos Olímpicos Rio 2016 e; (7) os Jogos Paralímpicos Rio 2016. Tais eventos mobilizaram e impactaram diversas cidades brasileiras, mas nenhuma outra como a cidade do Rio de Janeiro, que vem experimentando diversas atividades do referido porte desde o ano de 2007.

Parece haver consenso que os Jogos Olímpicos e Paralímpicos Rio2016 foram os megaeventos esportivos mais desafiadores, em termos de gestão, dada a sua complexidade. Por mais que os seus organizadores detenham expertise de edições anteriores, tais eventos apresentaram sua inerente peculiaridade e características consideravelmente diferentes que influenciaram diretamente na organização dos Jogos. Tais diferenças, como às relacionadas ao 
território, à cultura, ao distinto idioma, entre outros, impuseram dados novos para o projeto olímpico Rio 2016 (RODRIGUES; UVINHA, 2014).

O grande desafio dos Jogos de 2016 no Rio de Janeiro pôde ser constatado a partir de seus números: mais de 200 nações, 10.500 atletas olímpicos, 4.500 atletas paralímpicos, 28 esportes olímpicos, 22 esportes paralímpicos, mais de 100 mil pessoas diretamente envolvidas na organização, mais de 30 mil profissionais de imprensa e cerca de 100 mil voluntários. As competições aconteceram majoritariamente em quatro regiões olímpicas da cidade do Rio de Janeiro - Barra, Copacabana, Maracanã e Deodoro; além de outras cinco "cidades do futebol” - Belo Horizonte, Brasília, Manaus, Salvador e São Paulo. A Vila Olímpica e Paralimpíca era composta por 750 mil metros quadrados - o que equivale a 100 campos de futebol -, sendo disponibilizadas 17.700 camas, 9.460 quartos e 48 edifícios com apartamentos (RIO 2016, 2016a).

A expectativa inicial dos comitês organizadores locais era de um real impacto em 55 diferentes setores da economia brasileira, sendo o segmento de turismo um elemento de destaque. No entanto, tem-se questionado: quais seriam de fato os possíveis impactos nas cidades-sede nos mais diversos setores, entre eles o de turismo e de lazer? Qual a garantia de retorno a partir de massivos investimentos (em geral públicos) destinados aos megaeventos esportivos no Brasil? Quais as oportunidades geradas a partir destes eventos, como a possível geração de empregos e renda? (UVINHA, 2013).

O objetivo do presente texto é realizar um relato de experiências vividas durante as Olimpíadas Rio 2016. O período de análise compreende a realização do megaevento esportivo: 5 a 21 de agosto de 2016. Para isso, realizou-se uma pesquisa exploratória de âmbito qualitativo, viabilizada por uma observação participante, com a inserção do pesquisador na realidade em que se deram os fatos, no caso a cidade do Rio de Janeiro e também a de São Paulo, que foi uma das cidades do futebol, conforme apontado anteriormente. Tal inserção permitiu confrontar a realidade dos fatos com uma série de postulados teóricos e hipóteses formuladas anteriormente aos Jogos Olímpicos, servindo de excelente exercício, em especial, para o pesquisador temático aos megaeventos esportivos:

Todo pesquisador precisa ser um curioso, um perguntador. E essa qualidade deve ser exercida o tempo todo no trabalho de campo, pois este será tanto melhor e mais frutuoso quanto mais o pesquisador for capaz de confrontar suas 
Tourism in Analysis

teorias e suas hipóteses com a realidade empírica. Assim, o pesquisador não deve ser um formalista que se apegue à letra de seu projeto e nem um empirista para quem a realidade é o que ele vê, "a olho nu”, ou seja, sem o auxílio de contextualização e conceitos. Nem um nem outro, sozinho, contém a verdade. (MINAYO; DESLANDES; GOMES, 1993, p. 62)

Assim, será apresentado a seguir o relato de forma aleatória em termos de temporalidade, organizado pelos aspectos articulados com as regiões onde se deram os fatos e os fatores a ele associados (como a mobilidade turística, o usufruto de serviços, as experiências esportivas, entre outros). Para tal, serão utilizadas figuras durante o texto para melhor compreensão dos dados, como mapas oriundos de fontes secundárias e fotos registradas em campo pelo pesquisador.

\section{Um relato de campo sobre as Olimpíadas 2016}

A participação como atleta para a Olimpíada exige elevado esforço e preparação, com necessidade de dedicação de muitos anos para aquele especial momento de uma prova esportiva, que pode durar dias ou apenas alguns segundos. Guardadas as devidas proporções, o envolvimento de outros participantes nos Jogos também envolve certa preparação. Aqui se incluem, entre outros, os gestores do evento, os voluntários, a mídia especializada e até mesmo os espectadores que se dispõem a acompanhar, in loco, as mais diversas atividades em distintos horários e pontos da cidade.

Pode-se afirmar que o acompanhamento atento deste pesquisador teve início em 2 de outubro de 2009, dia oficial de aprovação da candidatura do Rio de Janeiro para as Olimpíadas de 2016 na sessão oficial do Comitê Olímpico Internacional, em Copenhague, Dinamarca. Desse dia até o evento, em agosto de 2016, iniciou-se a "corrida" por todas as informações inerentes à preparação para o evento, incluindo ingressos, hospedagem, transporte até a cidade do Rio de Janeiro, entre outras.

A aquisição de ingressos foi realizada por meio de informações, em grande parte, divulgadas no website oficial dos Jogos (RIO DE JANEIRO, 2016a). A escolha por uma ou outra sessão do evento seria contemplada basicamente por três fases: (1) fase de sorteio; (2) venda direta on-line; (3) venda direta na bilheteria. Os preços eram os mais variados, sendo as cerimônias de abertura/encerramento e final do futebol masculino nitidamente os mais disputados. 
Tourism in Analysis

O critério de escolha deste pesquisador seguiu a lógica de adquirir o maior número possível de ingressos, em distintos locais de competição e nas mais diversas modalidades esportivas. O processo de compra envolveu um verdadeiro exercício de paciência, atentando a um cuidado para que os horários de competições não conflitassem e que o deslocamento de uma região para outra (como por exemplo, da Barra para o Maracanã) fosse realizado com suficiente tempo. A Figura 1 traz um arranjo dos ingressos adquiridos para a Rio 2016, que incluem as Cerimônias de Abertura/Encerramento, partidas eliminatórias e partidas finais de diversas competições:

Figura 1 - Ingressos adquiridos para as Olimpíadas 2016

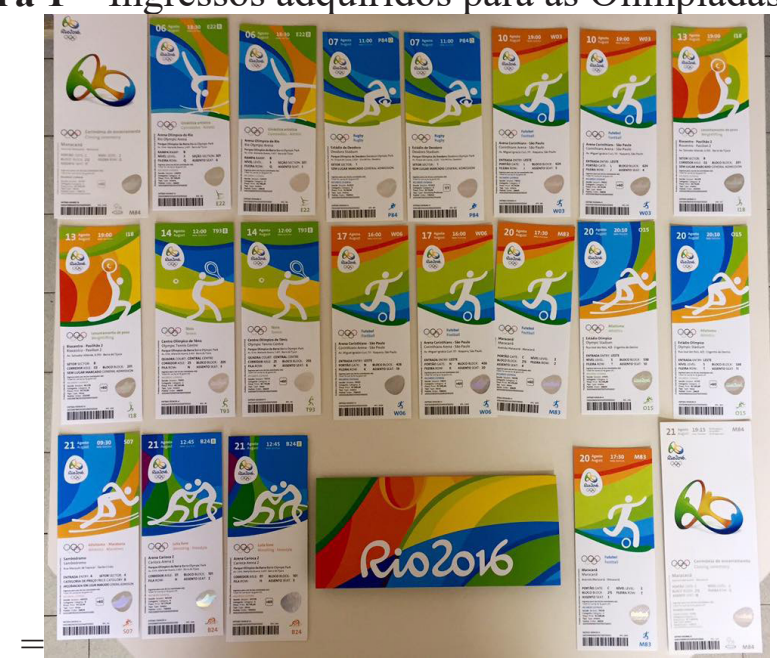

Fonte: Arquivo pessoal

Assistindo também às competições de futebol em São Paulo, fato que ainda será explorado neste relato, demandou-se a necessidade de viajar o trecho São Paulo/Rio de Janeiro/São Paulo em três oportunidades durante os Jogos - deslocamentos que foram realizados por carro, ônibus e avião. Tais deslocamentos permitiram uma análise sobre os serviços diretamente associados à mobilidade, como a preparação dos aeroportos, a condição das estradas, a oferta de serviços de transportes que exploram comercialmente tal trecho, entre outros.

$\mathrm{Na}$ cidade do Rio de Janeiro, os Jogos foram realizados em diversos pontos, mas principalmente nas quatro macro regiões estabelecidas para as competições. Foram elas: (1) Barra; (2) Deodoro; (3) Copacabana; e, (4) Maracanã. A Figura 2 ilustra em parte o desafio logístico enfrentado pela organização dos Jogos: 
Tourism in Analysis

Figura 2 - Mapa das regiões de competição

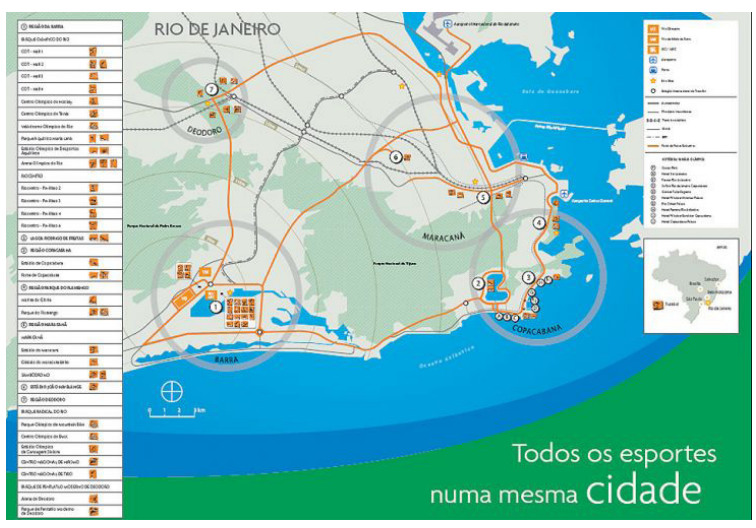

Fonte: Adaptado de Rio 2016 (2016)

Um dos maiores desafios na gestão dos Jogos Olímpicos na cidade do Rio de Janeiro se referia à mobilidade, esta que deveria ser ofertada aos milhares de turistas durante a competição. Tal transporte deveria integrar, com eficiência, as mencionadas regiões, bem como os aeroportos, portos e rodoviárias que servem a cidade. A Figura 3 retrata um mapa criado pela Prefeitura do Rio de Janeiro, amplamente divulgado durante os Jogos, para facilitar a locomoção na cidade:

Figura 3 - Mapa da rede de transportes da Rio 2016

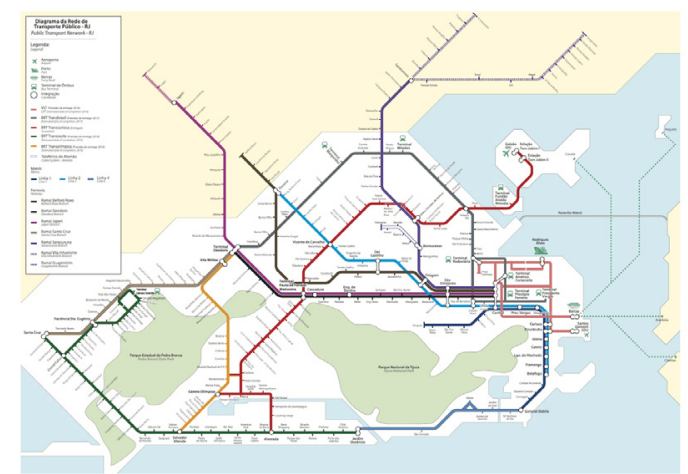

Fonte: Adaptado de Rede de transportes (2016)

Hospedado no bairro de Santo Cristo, na zona portuária carioca, o pesquisador teve a oportunidade de se locomover, no mencionado período de agosto de 2016, por meio de vários modais de transportes na referida cidade: (1) ônibus; (2) metrô; (3) trem; (4) veículo leve sobre trilhos - VLT; (5) bus rapid transit-BRT; (6) táxi; (7) Uber; (8) bicicleta; entre outros. 
Tourism in Analysis

Pôde-se verificar, por exemplo, o primeiro dia de operações da aguardada Linha 4 do metrô, inaugurada para o público no dia de abertura dos Jogos, ligando as estações General Osório, em Copacabana, até Jardim Oceânico, na Barra. Havia, aliás, muita expectativa em relação à inauguração desta nova linha, que, efetivamente, pôde ser utilizada pela população local somente depois do encerramento dos Jogos, já que era exigido o ingresso dos Jogos para adentrar a estação Jardim Oceânico, esta reportada na Figura 4:

Figura 4 - A nova estação Jardim Oceânico nas Olimpíadas 2016

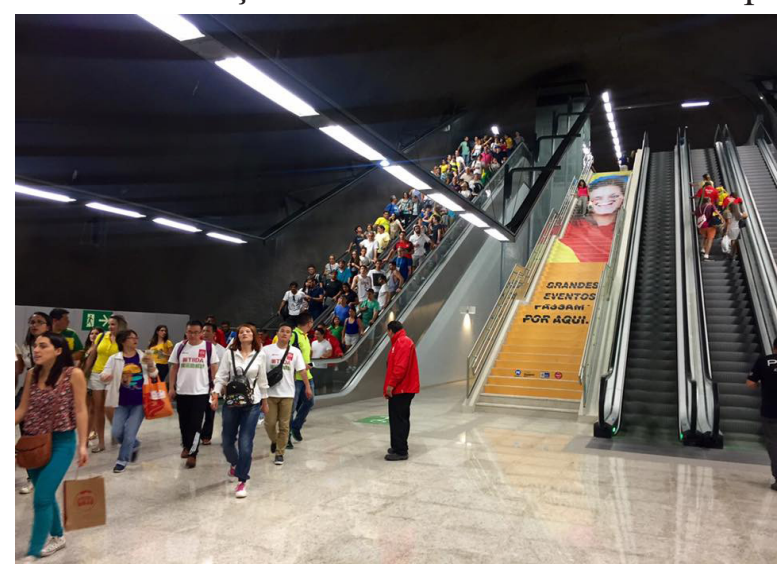

Fonte: Arquivo pessoal

Diante do elevado número de pessoas circulando pelos modais de transporte e pelos locais de competição foi necessária uma logística que envolveu funcionários das companhias responsáveis e, em especial, voluntários dos próprios Jogos ${ }^{2}$ - que também atuaram de forma relevante na orientação do público durante todo o evento, como destacado na Figura 5:

\footnotetext{
2 Mais informações sobre o importante papel desempenhado pelos voluntários dos Jogos podem ser visualizadas no website oficial \#SouVoluntário (RIO 2016, 2016b).
} 
Tourism in Analysis

Figura 5 - Voluntários “em ação” nas Olimpíadas 2016

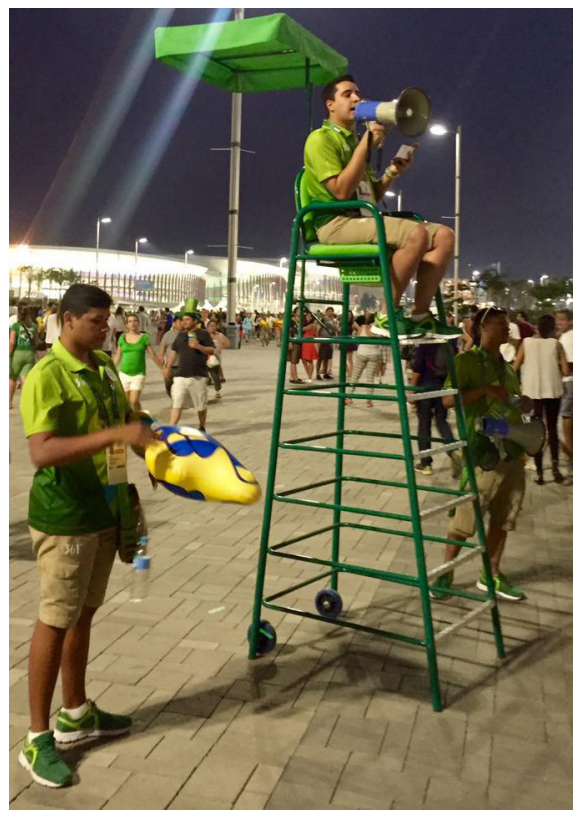

Fonte: Arquivo pessoal

Como era de se esperar, a circulação de pessoas foi intensa no Rio de Janeiro durante os Jogos Olímpicos. Conhecidos locais da cidade, como a praia de Copacabana (Figura 6), tornaram-se ponto de encontro para turistas estrangeiros e domésticos. O Forte de Copacabana, aliás, foi local de competição de diversas provas disputadas ao ar livre, como ciclismo de estrada, maratonas aquáticas e triatlo.

Figura 6 - Região de Copacabana nas Olimpíadas 2016

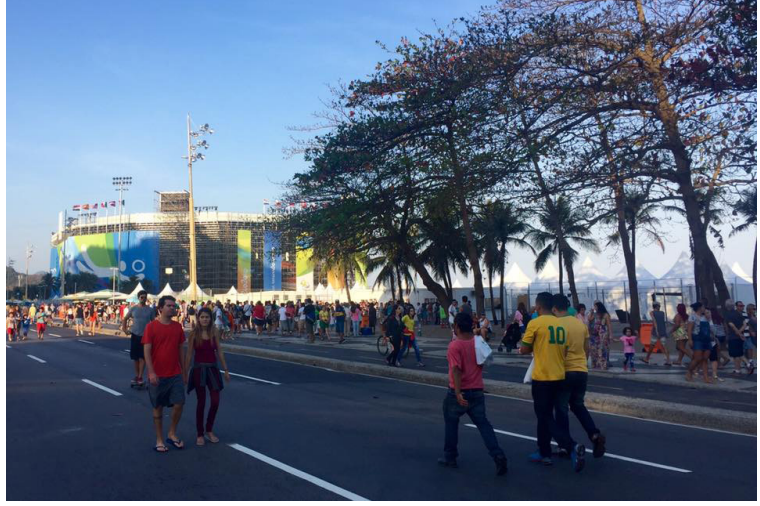

Fonte: Arquivo pessoal 
Tourism in Analysis

A circulação de pessoas expressava uma excelente oportunidade para a promoção da cidade a partir dos centros de informações turísticas, estrategicamente posicionados na cidade. Em um deles, localizado na praia de Copacabana, verificou-se um importante tráfego de turistas interessados nos diversos pontos de visitação da "Cidade Maravilhosa", estimulados por materiais amplamente distribuídos ${ }^{3}$ (Figura 7).

Figura 7 - Serviço Turístico na Praia de Copacabana

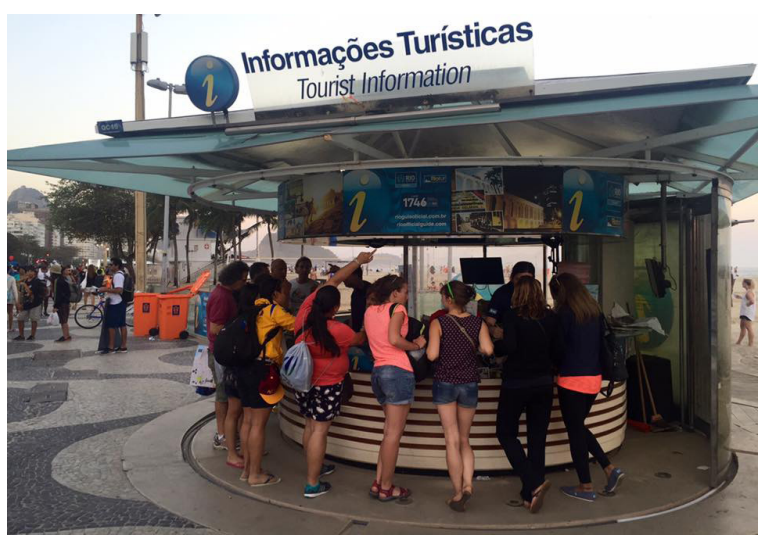

Fonte: Arquivo pessoal

Pôde-se presenciar que muitas das questões dos turistas se referiam aos locais de competição (como chegar, tempo de deslocamento, questões de segurança etc.). Como ressaltado, houve a oportunidade de assistir às competições esportivas em todas as quatro regiões olímpicas na cidade. Certamente, uma das que recebeu maior destaque foi a região da Barra, considerada pelo governo federal “O Coração dos Jogos 2016” (BRASIL, 2016).

A Barra da Tijuca abrigou o Parque Olímpico, as Vilas Olímpica e Paralímpica, entre outros importantes equipamentos para a realização dos Jogos. O Parque Olímpico ocupou uma área de 1,18 milhão de metros quadrados e foi a sede de 16 modalidades olímpicas na competição. Entre outras formas de modais de transporte, o local foi atendido por duas novas linhas de BRT, a Transolímpica e a Transcarioca. Aliás, o Parque Olímpico é considerado o principal legado dos Jogos Rio 2016,esperando-se que as instalações esportivas permanentes - compostas por três pavilhões: o Centro de Tênis, o Velódromo e o Parque Aquático Maria

\footnotetext{
3 Entre os vários materiais, sugere-se consulta àqueles distribuídos pelo Visit Rio (VISIT RIO, 2016) e pelo link especial "Informações ao turista" no website oficial da Rio 2016 (2016a).
} 
Tourism in Analysis

Lenk -, façam parte do futuro Centro Olímpico de Treinamento (COT), a ser gerido pelo Instituto Brasileiro do Esporte associado à Rede Nacional de Treinamento (BRASIL, 2016). Na Figura 8, o Parque Olímpico da Barra. Em destaque, as Arenas Carioca 1, 2 e 3. A Arena Carioca 1 sediou as competições de basquetebol nas Olimpíadas 2016 e estima-se que o local será transformado num espaço de treinamento de alto rendimento esportivo para as modalidades boxe e taekwon do, bem como uma estrutura que compreenderá academia de ginástica, auditório e espaço para shows diversos. Já a Arena Carioca 2, palco do judô e da luta olímpica, deve seguir no período pós-olímpico como espaço de treinamento para atletas de alto rendimento em diversas modalidades, tais como ginástica rítmica e de trampolim, judô, boxe, lutas, entre outras. A Arena Carioca 3, que sediou na competição a esgrima e o taekwon do, deve gerar como legado uma escola com mais de 20 salas de aula, refeitório e vestiários voltada para o esporte, recebendo alunos em período integral. Ainda na mesma figura, é possível visualizar a Arena do Futuro, que recebeu o handebol nas Olimpíadas e já foi projetada para ser desmontada logo após as Paralimpíadas, gerando aparelhamento esportivo para quatro escolas públicas com 17 salas de aula cada (O LEGADO..., 2016).

Figura 8 - Parque Olímpico da Barra nas Olimpíadas 2016

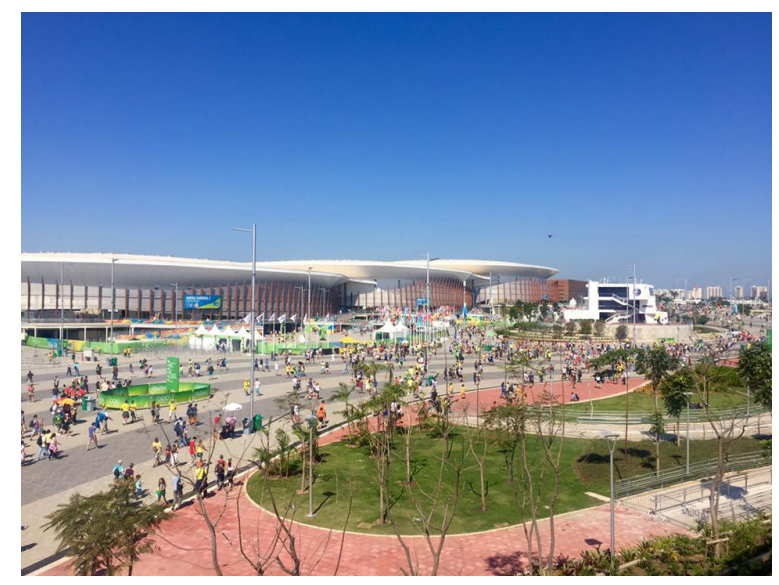

Fonte: Arquivo pessoal

No Parque Olímpico, o Centro Olímpico de Tênis recebeu tal modalidade no Rio 2016. O legado a ser gerado é a manutenção da quadra central, destaque da Figura 9, que deve passar a receber os mais importantes eventos internacionais da modalidade. 
Tourism in Analysis

Figura 9 - Centro Olímpico de Tênis nas Olimpíadas 2016

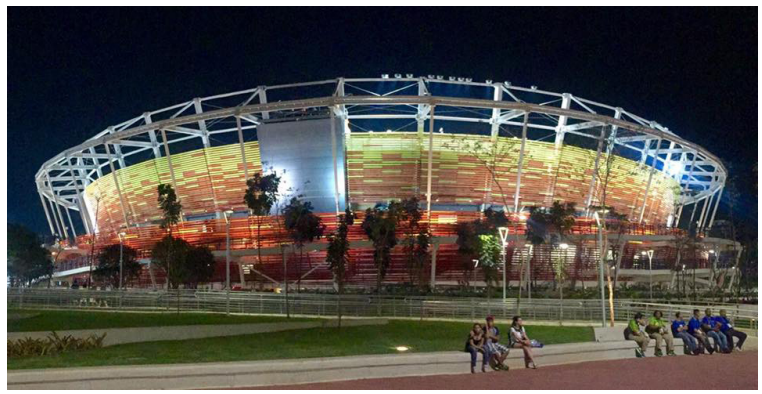

Fonte: Arquivo pessoal

Já a Arena Rio, ilustrada na figura 10, sediou os eventos de ginástica rítmica e artística e estima-se que sirva, como legado pós-evento, para continuar recebendo eventos esportivos, não necessariamente associados à ginástica (como basquete e lutas), e também shows e eventos culturais ${ }^{4}$

Figura 10 - Arena Rio, sede da ginástica nas Olimpíadas 2016

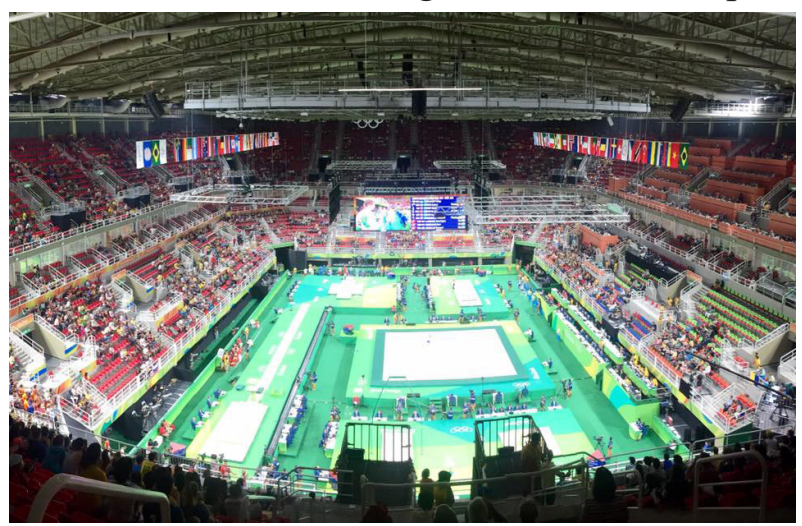

Fonte: Arquivo pessoal

Ainda no Parque Olímpico, o Estádio Olímpico de Esportes Aquáticos foi construído ao custo de R $\$ 217$ milhões e foi palco da natação e da fase final do polo aquático (Figura 11).

\footnotetext{
${ }^{4}$ Sobre as atividades culturais desenvolvidas no período pós-Jogos Olímpicos/Paralímpicos Rio 2016, recomenda-se consulta ao website Cidade Olímpica (RIO DE JANEIRO, 2016b), promovido pela Prefeitura da cidade do Rio de Janeiro.
} 
Tourism in Analysis

Figura 11 - Estádio Olímpico de Esportes Aquáticos

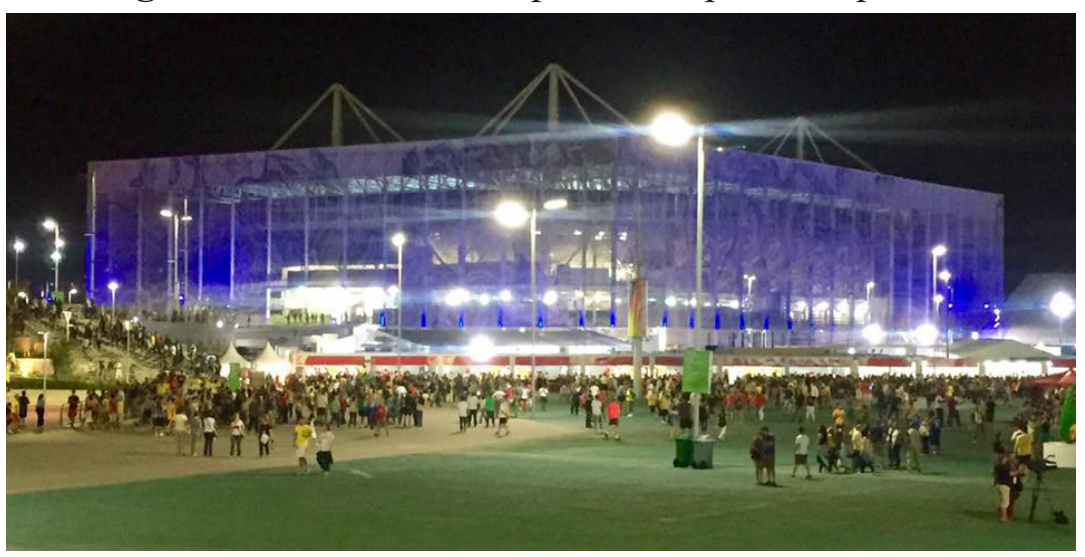

Fonte: Arquivo pessoal

Interessante notar o conceito de "arquitetura nômade" utilizado para a concepção de algumas estruturas esportivas nas Olimpíadas 2016. Tal conceito foi levado em consideração, a exemplo de Londres 2012, para implementar a relação custo-benefício dos equipamentos e para evitar os já conhecidos "elefantes brancos" oriundos de megaeventos esportivos, permitindo uso efetivo nos pós-jogos e acessível à população (O LEGADO..., 2016).

Já a região de Deodoro, localizada na região oeste do Rio de Janeiro ${ }^{5}$, sediou as competições de hipismo, ciclismo mountain bike e BMX, pentatlo moderno, tiro esportivo, canoagem slalom, hóquei sobre a grama, basquetebol e rugby - modalidade que foi inserida pela primeira vez nos Jogos Olímpicos de 2016, e que teve algumas partidas acompanhadas pelo pesquisador (Figura 12).

Figura 12 - Partida de rugby na região de Deodoro

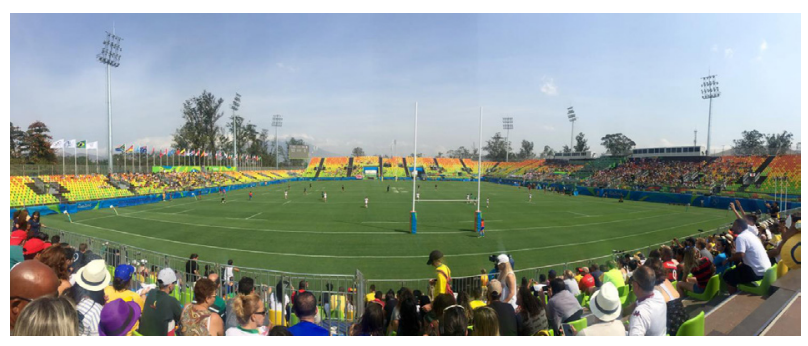

Fonte: Arquivo pessoal

\footnotetext{
${ }^{5}$ O Complexo Esportivo de Deodoro simbolizou uma interessante integração dos Jogos Olímpicos 2016 com os megaeventos esportivos anteriores, já que $60 \%$ das áreas de competição já haviam sido modernizadas graças aos Jogos Panamericanos 2007 e Jogos Mundiais Militares 2011 (BRASIL, 2016).
} 
Tourism in Analysis

Na zona central do Rio de Janeiro, até mesmo o famoso Sambódromo passou por reformas estruturais, com o acréscimo de novas arquibancadas para receber as provas de tiro com arco e a maratona, esta última tradicional prova dos Jogos Olímpicos (Figura 13).

Figura 13 - Sambódromo adaptado para a Maratona nas Olimpíadas 2016

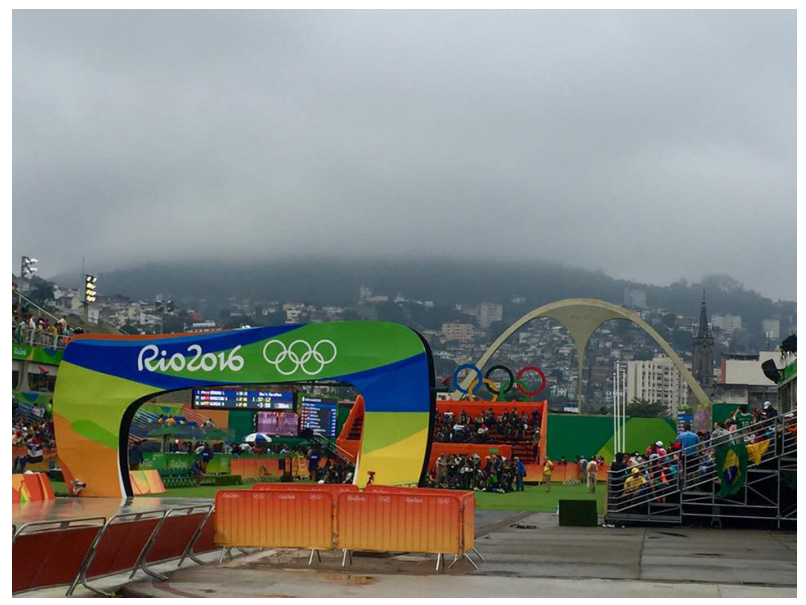

Fonte: Arquivo pessoal

A região do Maracanã foi por sua vez o palco das partidas decisivas da modalidade futebol. A final do futebol masculino nas Olimpíadas 2016 trouxe a tão aguardada "revanche" entre Brasil e Alemanha desde o revés brasileiro na Copa FIFA 2014. A Figura 14 é resultado de imagem captada momentos antes da cobrança das penalidades máximas, em partida que trouxe a inédita medalha de ouro para o Brasil na modalidade mais praticada do país.

Figura 14 - Final do futebol masculino nas Olimpíadas 2016: Brasil x Alemanha

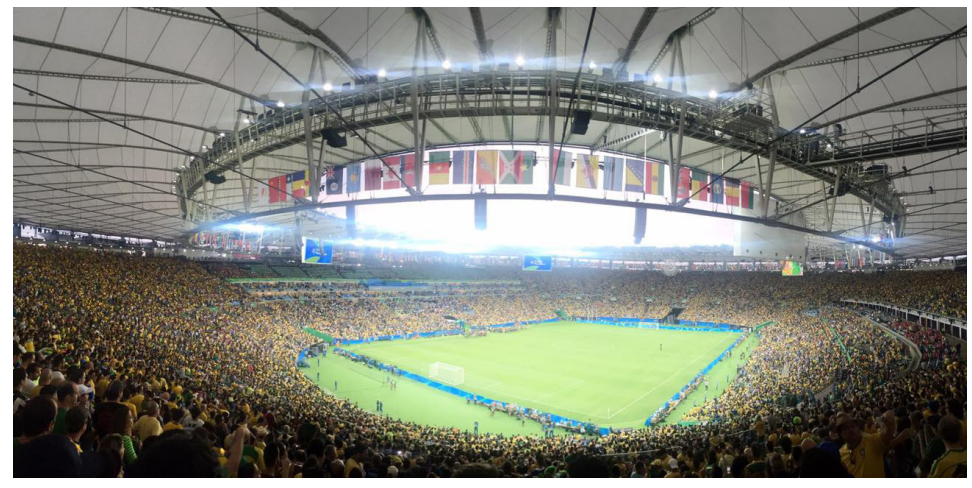

Fonte: Arquivo pessoal 
Tourism in Analysis

O Maracanã também foi palco das cerimônias de abertura e de encerramento dos Jogos. Na Figura 15 é identificado um dos momentos do encerramento, que trouxe uma homenagem a todos os atletas participantes da competição e uma performance organizada pela delegação do Japão, sede das Olimpíadas 2020.

Figura 15 - Cerimônia de encerramento das Olimpíadas 2016

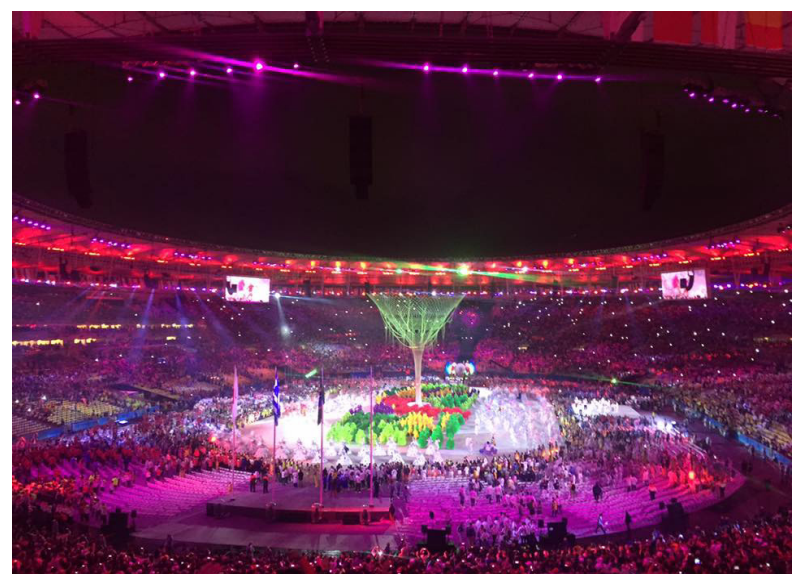

Fonte: Arquivo pessoal

Finalmente, ressalta-se que antes mesmo da cerimônia de abertura da Rio 2016, já era possível acompanhar as partidas da modalidade futebol em mais cinco cidades, além do Rio de Janeiro. Foram elas: (1) Belo Horizonte (Estádio Mineirão); (2) Brasília (Estádio Nacional Mané Garrincha); (3) Manaus (Estádio Arena Amazônia); (4) Salvador (Estádio Arena Fonte Nova); e (5) São Paulo (Estádio Arena Corinthians).

Em complemento à experiência do Rio de Janeiro, houve a oportunidade de acompanhar algumas das partidas realizadas em São Paulo. O estádio Arena Corinthians (Figura 16) foi oficialmente projetado para o mundo na partida inaugural da Copa do Mundo da FIFA, em 12 de junho de 2014, na qual o Brasil venceu a Croácia. Desde então, muito se discute sobre os investimentos realizados para a construção deste novo estádio em Itaquera, zona leste de São Paulo, bem como a possibilidade de utilização pela população também como um equipamento de lazer para além do futebol ${ }^{6}$.

\footnotetext{
${ }^{6}$ Em estudo recentemente publicado, é possível ampliar a discussão sobre o reconhecimento do estádio Arena Corinthians como um legado para a população da cidade de São Paulo, ao explorar possibilidades também associadas a um equipamento de lazer (PAULA; UVINHA, 2016).
} 
Tourism in Analysis

Figura 16 - Estádio Arena Corinthians nas Olimpíadas 2016

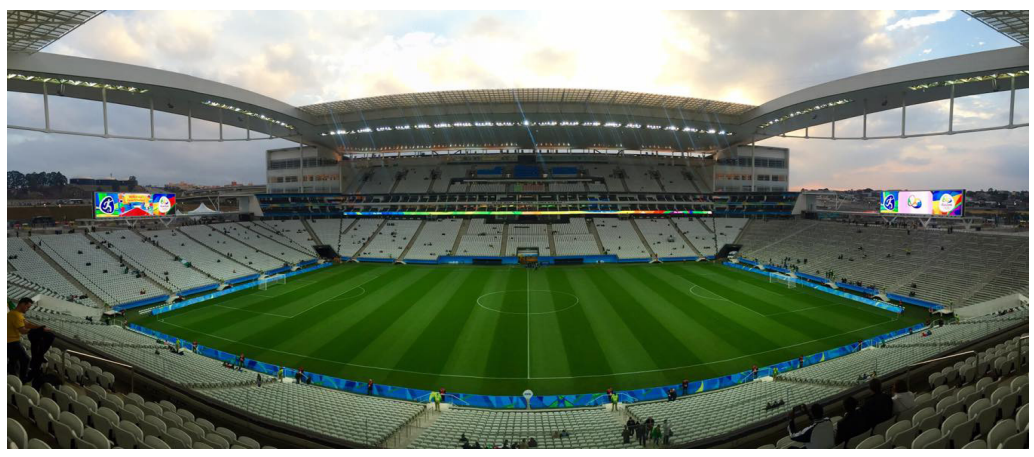

Fonte: Arquivo pessoal

Experiências como caminhar no Boulevard Olímpico do renovado centro da cidade; presenciar a estreia da mais nova modalidade olímpica, o rugby, no Complexo de Deodoro; observar as modernizações realizadas no Estádio Olímpico para as provas de atletismo; presenciar as finais do tênis, ginásticas e lutas no descrito Parque Olímpico; visualizar as adaptações do Rio Centro para as finais do levantamento de peso e no Sambódromo para a gloriosa maratona; e, claro, testemunhar, num Maracanã (lotado), as cerimônias oficiais e a emocionante final do futebol masculino. Enfim, o presente relato permite ao pesquisador retratar apenas uma pequena parte da emocionante oportunidade de estar in loco no maior evento esportivo do mundo, ocorrido pela primeira vez na América do Sul e que, como implicado, impactou diretamente diversos setores para além do esporte, entre eles o de turismo.

\section{Conclusão}

A globalização, em toda a sua complexidade, tem emergido nas últimas duas décadas como a maior força socioeconômica mundial. Em vários sentidos, o esporte tem sido seu principal elemento a partir da realização de grandes eventos e os agentes associados a esse processo. Muito para além do esporte, estima-se que os megaeventos esportivos no período 2007-2016 tenham trazido ao Brasil um inegável impacto em termos de legado para diversos setores, entre eles o de melhorias nos aeroportos, portos e transporte terrestre; na mobilidade urbana; na infraestrutura da cidade; na criação de leis de sustentabilidade e acessibilidade; na 
melhoria da inteligência da segurança do país; na melhoria dos serviços médicos; nas melhorias nas áreas de energia, telecomunicação e tecnologia da informação, entre outros.

Para efeitos de articulação com o segmento do turismo, é fundamental suscitar que tais benefícios também impactaram os recursos humanos implicados em tais eventos, com a aprendizagem de línguas estrangeiras, a capacitação profissional, a ampliação da rede hoteleira e a qualificação de seus recursos humanos, colaborando assim para a maximização do Brasil como destino turístico. Como é sabido, os gastos dos visitantes com hospedagem, gastronomia, transporte local, entretenimento e compras expressam um importante componente para a economia de muitos destinos, criando diversas oportunidades de emprego, negócios e desenvolvimento.

O balanço realizado pela Prefeitura do Rio de Janeiro no pós-Olimpíada destaca que a cidade recebeu 1,17 milhão de turistas, sendo 410 mil do exterior. Os turistas teriam gasto $\mathrm{R} \$ 424,00 /$ dia e a área de hotelaria registrou ocupação média de 94\% nas três semanas de competição. Entre os emissores de turistas estrangeiros, a liderança foi exercida pelos Estados Unidos, seguidos pela Argentina e Alemanha. Entre os turistas brasileiros, 43\% eram oriundos de São Paulo seguidos por Rio Grande do Sul e Minas Gerais, com gastos médios de R\$ 310,42/dia. Ainda segundo tal balanço, os Jogos Olímpicos impactaram positivamente a economia da cidade em estimular o aumento de $70 \%$ do comércio na região da zona sul em comparação com o mês de agosto de anos anteriores. Já na Barra da Tijuca, no centro e na zona norte, as vendas teriam aumentado em $30 \%$, e em outros pontos da zona oeste o aumento no comércio foi de $20 \%$ (BRASIL,2016).

Em que pesem todas as considerações críticas quanto aos exorbitantes gastos e às dificuldades de manutenção, entende-se que a Olimpíada 2016 ofereceu uma rica possibilidade de legado ao se tornar um agente indutor de melhorias da infraestrutura da cidade do Rio de Janeiro e das cidades-sede do futebol, já que impulsionaram, modernizaram e ampliaram a oferta de transporte público; aceleraram programas de valorização do meio ambiente; impulsionaram a agenda social e educacional; além de se tornar poderosa plataforma para divulgação internacional do país, algo especialmente relevante ao setor de turismo.

O presente texto expressou apenas um breve relato, a partir de um pesquisador com formação na área de educação física/esportes e com experiência nos estudos que articulam o turismo, o lazer e a hospitalidade aos megaeventos esportivos. Permite-se assim apenas uma visão 
Tourism in Analysis

parcial, uma espécie de "recorte" da realidade, sem nenhuma pretensão de criar um amplo registro fundante de novas teorias ou postulados. De todo o relato, espera-se que tenha sido suficientemente destacado que tal década esportiva no Brasil deveria permitir um constante monitoramento dos eventos realizados no país, realizando intenso debate com a sociedade sobre os reais impactos e legados, em termos de oportunidades, para as populações nas mais distintas realidades socioculturais e fomentando futuras pesquisas sobre o papel do turismo como um dos promissores segmentos associados aos megaeventos esportivos.

\section{Referências}

BRASIL. Portal oficial do governo federal sobre os Jogos Olímpicos e Paralímpicos de 2016. 2016. Disponível em: $<$ http://bit.ly/2gPk4Wj>. Acesso em: 5 nov. 2016.

O LEGADO Olímpico: Rio 2016. Jornal O Estado de S.Paulo, São Paulo, 2016. Disponível em: $<$ http://bit.ly/2gQT9Hb>.Acesso em: 1 nov. 2016.

MINAYO, M. C. S.; DESLANDES, S. F.; GOMES, R. Pesquisa social: teoria, método e criatividade. Petrópolis: Vozes, 1993.

PAULA, C. L.; UVINHA, R. R. Mundial FIFA 2014 en San Paulo y sus impactos: estadio Arena Corinthians como equipamiento de ocio. Pasos - Revista de Turismo y Patrimonio Cultural, v. 14, n. 5, p. 1241-1251, 2016.

RIO 2016. Site Oficial dos Jogos Olímpicos 2016. 2016a. Disponível em: <http://bit.ly/29Z0KmW>. Acesso em: 28 out. 2016.

\#Souvoluntário. 2016b. Disponível em: <http://bit.ly/2gR4UgQ>. Acesso em: 22 out. 2016.

RIO DE JANEIRO (cidade). Guia do espectador. 2016a. Disponível em: <http://bit.ly/2bMVlwi>. Acesso em: 25 out. 2016.

.Prefeitura do Rio de Janeiro. Cidade olímpica. Jogos Rio 2016. 2016b. Disponível em: $<$ http://bit.ly/2fU2Pih>. Acesso em: 5 nov. 2016.

Prefeitura do Rio de Janeiro. Rede de transportes. 2016c. Disponível em: <http://bit.ly/ 2gi15Ac>. Acesso em: 30 out. 2016. 


\section{TURISMO EM ANÁLISE vol 27, n.,3, Deecembro, 2016}

Tourism in Analysis

RODRIGUES, R.P.; UVINHA, R.R. A gestão dos megaeventos e o legado para o esporte e o lazer. In: TONDIN, G.; VIDAL, R.; FEIX, E. (Orgs.) Esporte e lazer no Brasil: divisão de responsabilidades entre os entes federativos. Porto Alegre: FUNDERGS, 2014. p.80-99.

UVINHA, R. R. Megaeventos esportivos: legados para o turismo e a hotelaria. In: MARCELLINO, N.C. (Org.). Legados de megaeventos esportivos. Campinas: Papirus, 2014, p. 107-122.

VISIT RIO. O que faz o Rio especial. 2016. Disponível em: <http://bit.ly/2gW6D3j>. Acesso em: 1 nov. 2016.

Recebido em: 16/11/2016

Aprovado em: 18/11/2016 